\title{
The Demand for Reproductive Health Care*
}

\section{Gauthier Tshiswaka-Kashalala and Steven F Koch*}

\author{
Department of Economics, University of Pretoria, Private Bag X20, Hatfield, Republic of South \\ Africa \\ ${ }^{\star}$ Corresponding author: Steven F. Koch. E-mail: steve.koch@up.ac.za
}

\begin{abstract}
Africa has higher rates of fertility than anywhere else, which limits the ability of a demographic transition to positively influence economic and socioeconomic prospects on the continent. This research delves into the ineffective implementation of fertility limiting preferences. We develop a theoretical model formalizing the various determinants of a woman's reproductive health behaviour during her reproductive years, focussing on choices related to effective contraception. The model incorporates the cyclicality and volatility of fecundity, paying particular attention to the stochastic nature of the reproduction process, as well as potential costs (such as lost wages and direct costs of purchase) and benefits (such as the ability to invest in her education and/or career) of being able to control or at least mitigate the volatility in the reproductive process. The model generates heterogeneity in the choice of contraceptive quality depending on both biological and economic factors. The nonparametic control function model, based on Malawian data, supports the notion that both biological and economic factors affect contraception decisions. The results suggest that fertility limiting preferences are being met, at least partially, in Malawi, and that the demographic transition is gaining traction.
\end{abstract}

Keywords: Health Production, Contraception Effectiveness, Nonparametric Analysis

${ }^{*}$ The authors would like to thank Economic Research Southern Africa for their financial support, as well as the William and Flora Hewlett Foundation, the Population Reference Bureau, and the University of Pretoria Vice Chancellor Academic Development Grant Program, as their support for one author's PhD was paramount to its completion. Both authors would like to thank James Heckman for encouraging this line of research and Alexander Zimper for his insightful comments related to theoretical clarity. We would also like to thank Jaap Abbring, Salvador Navarro, Rulof Burger, Saurabh Singhal, participants at the Midwest International Economic Development Conference and participants at the Economic Research Southern Africa Labour Workshop for their comments on previous drafts of this research, as well as comments made by two anonymous reviewers and John Hoddinott; the usual disclaimer applies. 


\section{Introduction}

A demographic transition, or lowering of fertility rates, in Africa has the potential to reduce youth dependency rates, freeing time for increased female labour force participation, while allowing parents to invest more in the health and education of each of their children. A transition is also expected to affect the age and structure of the current workforce and the productivity of the future workforce, which could, in turn, positively affect national savings, investment and economic growth (Bloom et al., 2009; Ashraf et al., 2013; Karra et al., 2017), as well as the economic prospects of women (as reviewed by Canning and Schultz, 2012). Health benefits from that transition, such as reduced maternal mortality (Cleland et al., 2012 ) and infant mortality (Chersich et al., 2017), are also expected. ${ }^{1}$

However, that transition has not been fully realized. It started later in Africa than in other regions, has fallen slower than in other regions and it is associated with higher desired family sizes than in other regions (Bongaarts and Casterline, 2012; Bongaarts, 2017); thus, the subSaharan population is projected to reach 3.9 billion by 2100 (United Nations, Department of Economic and Social Affairs, Population Division, 2015). Differences (between Africa and elsewhere) in the fertility transition underscore the 'African exceptionalism' (AE) hypothesis (Caldwell et al., 1992). Observations and stylized facts about AE include pronatalism (Caldwell et al., 1992), slow changes in fertility preferences and ideal family size (Bongaarts and Casterline, 2012), and inconsistent, if any, empirical associations between desires to limit pregnancy and observed unwanted pregnancy (Casterline and El-Zeini, 2014). ${ }^{2}$ Extrapolating from these observations, it is possible that sub-Saharan African fertility declines will be greatly affected by the implementation of existing fertility preferences, i.e., via contraception.

Socioeconomically, however, AE is concurrent with other problems, e.g., lower net primary and secondary school enrollment rates (in the African region than elsewhere), greater undernourishment, ${ }^{3}$ lower savings and lower foreign direct investment (Cleland and Machiyama,

\footnotetext{
${ }^{1}$ Poor reproductive health outcomes have been blamed for many economic hardships facing women and their children (Schultz, 2008); sexual and reproductive health problems account for $18 \%$ of the total global burden of disease, and represent $32 \%$ of the burden among women of reproductive age (Singh et al., 2010). Thus, universal access to reproductive health care was included within the Millennium Development Goals (Say and Chou, 2011), although progress fell expectations (Fathalla et al., 2006).

${ }^{2}$ Rossier et al. (2014), though, suggest that traditional methods are under-reported. Revising survey instruments to account for traditional methods leads to increases in contraception use amongst married women, which could alter the reported empirical inconsistency.

${ }^{3}$ According to Collier and Dercon (2014), the focus on smallholder farming on the continent holds back the potential of agriculture to harness economies of scale. Thus, under-nourishment could worsen further, since
} 
2017). Furthermore, although a few African countries are good places to do business (i.e., they are amongst the top $50 \%$ of countries in which to do business), 12 rank in the lowest 10\% (World Bank, 2014), while 22 of 28 fragile states are African (Marshall and Cole, 2014). Although we are not aware of evidence suggesting that AE is behind these problems, less exceptionalism is expected to benefit the economic, political and health prospects of the continent.

According to Moultrie et al. (2012), speeding up the transition requires contraception adoption. Fortunately, more women want effective contraception now than in the past (Darroch and Singh, 2012), regional trends also suggest increases in uptake (Tsui et al., 2017), and contraception knowledge has risen (Blackstone et al., 2017). Thus, the evidence points to an increase in contraceptive demand on the continent; however, there remains ineffective implementation of fertility limitation preferences (Casterline and Agyei-Mensah, 2017). In other words, it is not just the adoption of contraception, but also the adoption of effective contraception. Thus, additional research to understand the adoption of effective contraception is warranted, as it can provide input into family planning policy formulation (Bongaarts and Casterline, 2012; Casterline and Agyei-Mensah, 2017).

Research into effective contraception adoption follows two rather different approaches. In the first, contraception is categorized as either modern or traditional, where modern implies effective - one contribution of our research is to incorporate a more nuanced definition of effectiveness (see Trussell, 2007, 2011; World Health Organization, Department of Reproductive Health and Research (WHO/RHR) and John Hopkins Bloomberg School of Public Health/Center for Communication Programs (CCP), Knowledge for Health Project, 2011). Such research focuses on the correlates of modern adoption, including community-level factors, finding that education, including partner's education, and wealth (see Thomas and Maluccio, 1996; Stephenson et al., 2007, for example), as well as various community-level and district-level factors are important correlates of modernity. Similarly, exposure to media, own and partner approval of family planning services (Stephenson et al., 2007) and female empowerment correlate positively with modernity (Do and Kurimoto, 2012).

In the second, although the effectiveness of contraception is not directly investigated, it is implied, due to changes in fertility that are observed. For example, one year of addiincreased populations could lead to even smaller farms per farmer. 
tional schooling, arising from the expansion of universal primary education, reduces births (per women aged 25) by 0.26 (Osili and Long, 2008). Similarly, schooling subsidies reduce dropout and teen pregnancy; however, an education program (focusing on abstinence) did not affect teen pregnancy, while a condom education program did not affect its use (Duflo et al., 2015). On the other hand, unconditional cash transfers for girls did more to reduce pregnancy (by 27\%) in the two-year study period than a conditional transfer (Baird et al., 2011). Although evidence from a Zambian cash transfer finds no impact (Palermo et al., 2016), a Zambian voucher scheme subsidizing contraceptives increased contraceptive takeup, improved mental health and reduced births in the short term (Ashraf, Field and Lee, 2014; Ashraf, Field and Leight, 2014; Ashraf, Buessing, Field and Leight, 2014). Additional studies find that contraception access decreases fertility in Tanzania (Angeles et al., 1998), Bangladesh (Phillips et al., 1982) and Colombia (Miller, 2010), but not in Ethiopia (Desai and Tarozzi, 2011) or Indonesia (Gertler and Molyneaux, 1994; Pitt et al., 1993).

The above suggests that family planning services will be used, if their costs are lower, but it is not very informative about the contraception choices that might be made. Thus, little is known about the effectiveness of contraception that is chosen by women, when they do choose to use contraception, and there is little evidence to explain why there is poor implementation of existing fertility preferences. ${ }^{4}$ A few recent exceptions are of note. McKelvey et al. (2012) identify very small price effects associated with contraception demand in Indonesia; although they find evidence of substitution between methods, as well as relatively large effects associated with reduced availability of contraception, they do not explicitly incorporate the uncertainty associated with the reproductive process or the effectiveness of the contraception. Tshiswaka-Kashalala and Koch (2017) incorporate a few aspects of the aforementioned uncertainty, finding that more educated women are better able to use contraception, regardless of the innate effectiveness of that contraception, to control the timing of their first birth.

Thus, the main objective of this study is to answer a basic question related to how people adjust their demand for family planning services in an uncertain environment, paying particular attention to the 'quality' of those services. To meet this objective, we revise

\footnotetext{
${ }^{4}$ Recent reviews suggest further, but related, avenues of scrutiny. The effects of family programs remains an unsettled issue, and there is need to examine the quality of the family planning service and consider, at least in the case of vouchers, potential integration into the health system and scale-up (see Bongaarts, 2014; Bellows et al., 2016).
} 
ideas from Easterlin (1975) to formalize the interactions between various determinants of a woman's reproductive health behavior during her reproductive years, focussing specifically on reproductive health care. In principle, a women (or couple) would determine the amount (and quality) of contraception she will use after balancing the benefits against the costs of a particular type of family planning 'service'. The costs of family planning services include both transaction costs, in the form of search and information costs, as well as the monetary and psychic costs associated with using a particular contraception method. In addition, we make explicit the fact that the reproductive process is stochastic, which should influence the decision-making process. Thus, we contribute to the literature through the explicit incorporation of the stochastic nature of the reproductive process. The behavioural implications of our model are threefold. Firstly, as expected, reproductive health care quality is inversely related to its marginal costs; there is substitution towards less effective methods in the face of higher costs. Secondly, there is a positive relationship between the effectiveness ('quality') of a woman's contraceptive strategy, her natural fecundity rate and frequency of intercourse, as increased possibilities of pregnancy are offset by improved contraceptive methods. Thirdly, there is a positive relationship between the risk (degree of uncertainty) in the reproductive process and the effectiveness of contraception. Even though the model is not inherently about risk preferences, preference concavity implies contraceptive self-insurance.

The theoretical implications of the model are empirically examined, using data from the 2010 Malawi Demographic and Health Survey (2010 MDHS). One of the primary features of the theoretical analysis is that the 'quality' of contraception is an important component of the decision-making process. Therefore, we make a further contribution to the literature by incorporating quality into our empirical analysis of family planning. Quality is informed by recent estimates of contraceptive efficacy (see Trussell, 2007, 2011; World Health Organization, Department of Reproductive Health and Research (WHO/RHR) and John Hopkins Bloomberg School of Public Health/Center for Communication Programs (CCP), Knowledge for Health Project, 2011). The theoretical analysis suggests that the aforementioned relationships could be non-linear. Furthermore, within our structure, the frequency of intercourse is likely to be endogenous to the contracepting decision. Endogeneities might also arise, because we are not able to directly capture risk preferences. Thus, we nonparametrically estimate our model of the demand for contraceptive effectiveness using the nonseparable empirical 
framework described in Florens et al. (2008) and Imbens and Newey (2009).

\section{The Model}

Following the tradition started by Grossman $(1972,2000)$, we could consider family planning services to be both a consumption and investment good. As a consumption good, contraception is an economic 'bad' - it is a potential source of discomfort at a particularly inconvenient time. As an investment good, family planning services can be viewed as an input to lifetime earnings (Ben-Porath, 1967; Kaestner, 2013), which people maximize, subject to the dynamic path of the stock of reproductive health capital. However, we make two observations regarding the traditional model. First, while health care (as a final good) should enter an individual's utility function, health itself (as one of the multiple forms of human capital) should not be an argument in the individual's utility function, since it can hardly be acquired as a final good (Ben-Porath, 1967; Kaestner, 2013). Thus, in our version of the model, health care enters the individual's utility function, while health capital appears in the earnings function. Second, the human reproduction process is both cyclical and stochastic in nature; therefore, a woman's capability to reproduce and her freedom to plan childbearing largely depend on both biological factors (such as the woman's natural ability to conceive and the characteristics of her partner's semen) and behavioural factors (such as her contraceptive behaviour and sexual practice). In this setting, the role of family planning services, rather than being a direct investment into new reproductive health capital, is mainly to prevent stochastic 'deterioration' of the stock of reproductive health; we refer to deterioration in our model as increasing the probability that a woman becomes pregnant.

The view of good reproductive health espoused here is that it represents the capability to reproduce and the freedom to decide if, when and how often to give birth. In the case of a fecundable woman, this capability is generally higher within a particular age range and is influenced by the random nature of the human reproduction process (Perrin and Sheps, 1964). It is also characterized by fluctuations in the woman's natural fecundity. We suppose that these fluctuations can be controlled (imperfectly) through a specific contraceptive behaviour. The fact that the woman's rate of natural fecundity is explicitly incorporated into the model, not only accounts for heterogeneity among contracepting women, but also intro- 
duces uncertainty into the analysis. Thus, we allow for a stochastic evolution of reproductive health capital, as a result of uncertainty in the woman's natural fecundity (Heckman and Willis, 1976).

Consequently, assuming imperfect control over the probability of falling pregnant, our analysis explicitly incorporates the uncertainties surrounding the human reproduction process. The equation of motion in reproductive health is modelled as being partly determined by the deterministic natural investment in reproductive health and partly by a random factor following a standard Brownian motion. The choice of a standard Brownian motion to drive fluctuations in the stock of reproductive health capital is well-suited to the continuous time setting of our model. ${ }^{5}$ We then apply stochastic control theory in order to derive analytic solutions with behavioural content, and, thus, policy implications.

Consider a dynamic fertility model in which fluctuations in reproductive health capital depend on the woman's probability of getting pregnant; those fluctuations are driven by a standard Brownian motion $B=\left\{(B(t)), \mathcal{F}_{t}\right\}_{t \geq 0}$ defined on the probability space $\left(\Omega, \mathcal{F}_{t}, P\right)$. The standard Brownian motion is one of the most common forms of continuous random shocks in the literature, where the relevant variable is subjected to a continuous series of random disturbances, and the optimal time path of the control variables must continuously compensate for shocks (Laporte and Ferguson, 2007). We suppose that $\left\{\mathcal{F}_{t}\right\}_{t \geq 0}$ is the augmentation of filtration, and this drives the family formation process.

Assume, also, that a fecundable woman has some control over the fluctuations in the stock of reproductive health capital $k(t)$ through her contraceptive behaviour, such that $k$ evolves according to the following stochastic process, where $\sigma d B(t)$ captures the variability $(\sigma)$ of the shocks $d B(t)$ within the system of Brownian motion:

$$
d \log k(t)=g(k(t)) d t+(1-m(t)) p(t) \chi(t) \sigma d B(t) .
$$

We define $g(k(t))$ as the natural improvement in the stock of reproductive health capital, while medical care in the reproductive health model captures contraception, specifically the control effectiveness of contraception, and it must lie in the unit interval; thus, $0 \leq m(t) \leq 1$.

\footnotetext{
${ }^{5}$ There are other stochastic extensions. For example, Laporte and Ferguson (2007) discuss a case where the stochastic nature of health is driven by a random factor with a Poisson distribution, while Liljas (1998) and Picone et al. (1998) introduce uncertainty in the Grossman model through the incidence and size of illness.
} 
Furthermore, the biological component of fecundity is defined as a rate, which also must lie in the unit interval; therefore, $0 \leq p(t) \leq 1$. Finally, $\chi(t)$ represents the frequency of sexual intercourse. Both perfect contraception (i.e. $m(t)=1$ ) or infertility $($ i.e. $p(t)=0)$ would solve uncertainty in the dynamics of $k(t)$, and these are incorporated in the model.

If good reproductive health can be assumed to give rise to more, or 'better', time, the benefits of contraception could include more time in the labour market, as well as greater child quality, in the event there are children in the household. With this in mind, we define a benefits function $y(t)=y(k(t))$, where $y_{k}>0$. As noted before, deterioration in this stock is assumed to lead to pregnancy and to birth, reducing the woman's effective time. In this setup, a contracepting woman's optimization problem becomes

$$
\begin{aligned}
V(t) & =\max _{m(t)} \mathrm{E}_{0}\left[\int_{0}^{t} e^{-r t}\{y(k(s))-h(m(s))\} d s+e^{-r t} v(k(t))\right] \\
\text { subject to } & \\
d \log k(t) & =g(k(t)) d t+(1-m(t)) p(t) \chi(t) \sigma d B(t) \\
0 & <m(t), k(0)
\end{aligned}
$$

where $h(m(t))$ represents the economic and non-economic costs of contraception to individuals. While economic costs would mainly include monetary expenses, there are significant non-economic costs for using birth control, such as the fear of side effects, social disapproval and spousal resistance, as well as unnecessary medical barriers (Casterline and Sinding, 2000; Bongaarts, 2010), and, of course, not having a child. We note further that health capital is attached to an individual and not resellable (Grossman, 1972; Arrow, 2006). Thus, $v(s)=y(k(s))-h(m(s))$ represents the return to investing in reproductive health care in time period $s$.

If we assume that the woman's objective is to maximize the expected current flow of benefits plus the expected change in future benefits caused by the drift in and the volatility of her reproductive health capital (Stokey, 2009; Bjork, 2009), the value function $V$ together 
with the optimal choice of $m(t)$ satisfy the Hamilton-Jacobi-Bellman (HJB) equation

$$
r V=\max _{m(t)}\left\{y(k(t))-h(m(t))+[g(k(t))] V_{k}+[(1-m(t)) p(t) \chi(t)]^{2} \sigma^{2} V_{k k}\right\}
$$

where $V_{k}>0$ and $V_{k k}<0$ represent the first and second derivatives of the value function with respect to reproductive capital.

The first order necessary condition provides an expression for the optimal contraceptive strategy: at the optimum, the marginal cost of contraception is equal to the marginal benefit of contraception, as measured by the reduction in the magnitude of the random shocks to the stock of reproductive health capital

$$
h_{m}(m(t))=-(1-m(t)) p^{2}(t) \chi^{2}(t) \sigma^{2} V_{k k} .
$$

If we also assume that the woman's total cost of contraception has a fixed component related to market cost, $\pi$ per unit of contraceptive effectiveness, as well as a net child cost $(c)$, such that

$$
h(m(t))=\pi m(t)+c(m(t))
$$

it follows, after setting $h_{m}=\pi+c_{m}$ in (1) and solving, that the optimal quality of contraception for a sexually active woman would be

$$
m(t)=1+\frac{\pi+c_{m}}{p^{2}(t) \chi^{2}(t) \sigma^{2} V_{k k}}
$$

Other things being equal, the expression in (3) includes a few implications. As expected, since the model explicitly takes into account the impact of the cost of family planning services on a woman's contraceptive behaviour, the effectiveness of a woman's contraceptive strategy, $m(t)$, is negatively linked to the market opportunity cost of contraception services, $\pi$ (recall $V_{k k}<0$ by assumption). Faced with higher costs of family planning services, contracepting women will settle for less effective contraceptive methods. The opposite is also true if family planning services are made more affordable. In the extreme case where the cost of family planning is zero and there are no net marginal child costs, the model in (3) predicts that contracepting women will choose the best contraceptive method available, $m(t)=1$. The 
same implication arises for women who do not want children, i.e., $c_{m} \rightarrow-\underline{c}$. For women who want children, $c_{m} \rightarrow \bar{c}$, women choose not to use contraception; however, given the stochastic nature of the reproductive process, there is a nonzero probability that they may not become pregnant.

In addition to the standard results on prices, the model further suggests that the effectiveness of a woman's contraceptive strategy, $m(t)$, increases with natural fecundity, $p(t)$, and frequency of intercourse $\chi(t)$, although those conclusions are dependent, in part, upon $c_{m}$ not being too negative; women entirely opposed to an additional child in the household are not expected to be as responsive to price, for example. Since fecundity is also a cyclical event, it is possible that contracepting women will use more effective contraceptive methods only when they are more at risk of falling pregnant. Similarly, women who frequently have intercourse are also more likely to use relatively more effective contraceptive methods. One final pivotal result relates to uncertainty in the reproduction process. Although the results imply that increased volatility in the stochastic process leads to increased contraceptive effectiveness, there are also risk preference implications. In particular, increased risk aversion, which could be measured through a larger (more negative) second derivative of the value function, increase the effectiveness of contraception, as well. This last effect is expected to be enhanced through larger variability in the reproductive process.

\section{Empirical Analysis}

The preceding analysis yielded an expression for the demand for contraception effectiveness, $m(t)$, as a nonlinear function of the observed cost of contraception, $\pi+c(t)$, frequency of sexual intercourse, $\chi(t)$, the latent woman's natural fecundity, $p(t)$, a measure of the woman's risk preferences and the degree of uncertainty in the reproduction process. The nonseparable relationship between the variables in (3) implies that the effect of random variation in one factor on contraception effectiveness will vary with all the other covariates in the model (Chesher, 2003). In this context, nonseparability provides for the possibility that otherwise comparable women, in terms of one observable, will adopt contraceptive methods that differ, due to different interactions among the remaining variables in the model. Our empirical analysis will account for this possibility. 
A similar issue arises with respect to potential other factors. For example, consider the frequency of intercourse, which captures a woman's sexual activity (Brown, 2000). We postulate that, while it is true that sexual activity is a sine qua non for human reproduction, sexual intercourse is also a source of pleasure and may even be a source of income (Moffat, 2005; Smith and Christou, 2009; Hakim, 2010). In other words, we assume that frequency is also a choice, and, therefore, is endogenous, in the sense that it may be taken jointly with the contracepting decision. The model also underscores an important role for risk preferences. Since risk preferences are not easily uncovered in the data, there is another source of potential endogeneity in the model. Given these two sources of endogeneity, otherwise identical women are likely to have different contraceptive strategies for the same level of coital frequency.

If sexual activity is for the purposes of family formation, it is expected to mirror the menstrual cycle, and, therefore, the peak of sexual activity should occur approximately two weeks following the end of the most recent period. If, on the other hand, sexual activity is not for the purpose of family formation; rather, it is an expression of love between the couples, the peak of sexual activity is likely to occur at a different time in the menstrual cycle. More specifically, if sexual activity is not for the purpose of family formation, we would expect to see a lull in sexual activity around the peak of pregnancy risk, rather than a spike. Furthermore, if sexual activity was not for the purpose of family formation, we would expect more effective contraception to be used by women engaging in sexual activity no matter what the timing of pregnancy risk.

In what follows we attempt to isolate the heterogeneous impact of the frequency of sexual activity on contraceptive effectiveness by estimating an econometric model with essential heterogeneity in outcomes (Heckman et al., 2006). Since the frequency of intercourse is considered to be a continuous treatment, we adopt the control variable approach, which estimates the demand for contraception effectiveness based on a triangular simultaneous equations model. The identification and estimation of this type of model, one with nonseparable disturbances, has been discussed at length in the literature (Chesher, 2003; Florens et al., 2008; Imbens and Newey, 2009).

A generalized econometric formulation of our economic model is given by the non-separable model 


$$
m=(X, \varepsilon),
$$

where $m$ is contraceptive effectiveness (Berkson, 1944), $X$ is a vector of covariates including the endogenous frequency of sexual intercourse $\chi(t)$, and $\varepsilon$ is a general disturbance vector representing heterogeneous volatility in the value function.

Our empirical strategy closely follows the control variable technique discussed in Imbens and Newey (2009). In their analysis, the first step consists of building the control variable from the choice equation, before obtaining, in the second step, the conditional expectation of the outcome, given the endogenous variable and the control variable. Furthermore, Imbens and Newey (2009) show that, given a choice equation that is monotonic in a scalar disturbance, the conditional cumulative distribution function of the endogenous variable, given the instruments, is a control variable.

Therefore, we assume that the choice of sexual intercourse frequency is described by the following nonseparable treatment choice model

$$
\chi=\varphi(Z, \epsilon),
$$

where $\varphi$ is a strictly monotonic function in $Z$ and the scalar unobservable, $\epsilon$, representing the woman's taste for intercourse. The instrument, $Z$, captures the observed socio-economic environment, which determines a woman's sexual behaviour, but not her contraceptive behaviour, while $\epsilon$ captures the latent taste for sexual intercourse. The strict monotonicity in $\epsilon$ implies that a heightened state of interest in intercourse will induce higher frequency of sexual contacts, and is essential to the derivation of the control variable. Imbens and Newey (2009) show that, under independence of $(\epsilon, \varepsilon)$ and $Z$, the conditional cumulative distribution function $(C D F)$ of $\chi$, given $Z$, is a control variable

$$
v=F_{\chi \mid Z}(\chi, Z)=F_{\epsilon}(\epsilon),
$$

such that conditioning on the control variable $v$ leads to the identification of structural effects of any change in $X$ from the conditional distribution of $Y$, given $X$ and $v$. Note that the CDF in (6) can be estimated using standard nonparametric procedures, such as the ones outlined 
in Li and Racine (2008).

In summary, our empirical strategy is carried out in two steps. The first step estimates the control variable from the choice equation, and in the second stage the estimated control variable is plugged into the outcome equation, as an additional covariate, in order to make any change in $X$ causal. In other words, the second step involves estimating the output equation in (4) with the control variable estimates $\widehat{v}=\widehat{F}_{\chi \mid Z}(\chi \mid Z)$ from the first step in (6) as an additional co-variate. In particular, we nonparametrically estimate the following outcome model

$$
m=g(X, \widehat{v})+\varepsilon,
$$

where $g(\cdot)$ is an arbitrary function estimated from the data. The nonparametric model is estimated following the methods in Li and Racine (2004). We estimate both stages of the model in R (R Core Team, 2015) with the np package (Hayfield and Racine, 2008). Optimal bandwidths for the conditional distribution function in the first-stage are derived from leave-one-out least squares cross-validation ( $\mathrm{Li}$ et al., 2013), while optimal bandwidths for the second stage nonparametric regression are also derived from leave-one-out least squares cross-validation (Li and Racine, 2004). These methods have the benefit of being insensitive to irrelevant regressors (Hall et al., 2007). For continuous variables, a second-order epanechnikov kernel was used, and for ordered categorical predictors, the one suggested by Li and Racine (2007) was used. The choice of kernel does not particularly affect the estimation, the bandwidth does - see Li and Racine (2007) - thus our focus on estimating optimal bandwidths.

\section{Data}

The information we use for the empirical analysis comes from two modules of the 2010 Malawi Demographic and Health Survey (MDHS): the module on Reproductive Behaviour and Intentions and the Contraception module (see National Statistical Office (NSO) and ICF Macro, 2011). The module on reproductive behaviour and intentions records answers to questions about fertility history, current pregnancy status, fertility preferences, and the future childbearing intentions of each woman. The contraception module documents answers about knowledge and use of specific contraceptive methods, source of contraceptive methods, 
exposure to family planning messages, informed choice, and unmet needs for family planning.

\subsection{Contraception Effectiveness}

We measure contraceptive effectiveness with contraceptive use histories collected in the contraceptive calendar of the 2010 MDHS. A standard DHS contraceptive calendar records, for each woman, information about contraceptive status, births, pregnancies, reasons for discontinuing a method, and marital status by calendar month over, at minimum, a sixty month period preceding the survey. This information can be used to analyse the efficacy and continuity of women's contraceptive use (Ali and Cleland, 2010; Ali et al., 2012). For our analysis, we derive the average effectiveness of the woman's contraceptive strategy by first, matching each method with its published effectiveness during "typical use" (Trussell, 2011; World Health Organization, Department of Reproductive Health and Research (WHO/RHR) and John Hopkins Bloomberg School of Public Health/Center for Communication Programs (CCP), Knowledge for Health Project, 2011), and then taking the average over the duration of the reproductive calendar; we do not count months during which the woman was pregnant and we do not include women who have had a hysterectomy, are no longer menstruating or are otherwise infecund. This operation produces contraception effectiveness as a continuous variable taking values between 0 and $1: 0 \leq m \leq 1$.

Using data from the United States of America, Table 1 shows some standard contraceptive methods against their level of efficacy during "perfect use", when the method is used correctly and consistently (as directed) and during "typical use", which is how effective the method is during actual use. As can be seen, there are some marked differences in efficacy. ${ }^{6}$

Combining information on the effectiveness of standard methods in their typical use from Table 1 with data on contraceptive behaviour from the 2010 MDHS reproductive calendar suggests that women in Malawi are increasingly using more effective contraceptive strategies. The percentages in Figure 1 show that the average effectiveness of contraception used by a woman of reproductive age in Malawi has increased from 2005 to 2010. In 2005 the average effectiveness of contraception in the country stood at $28.16 \%$. This percentage slowly

\footnotetext{
${ }^{6}$ In our computation of the average effectiveness of a woman's contraceptive strategy, we assume that, since the category "other folkloric contraceptive methods" as recorded in the DHS contains family planning methods with no scientific proof regarding their effectiveness, using them is actually not different from not using any contraceptive method at all.
} 
Table 1: Contraceptive Effectiveness and Usage: Rates of Unintended Pregnancies per 100 Women during the First Year of Use and Usage Patters in Malawi 2010 DHS Data

\begin{tabular}{|c|c|c|c|c|}
\hline \multirow[b]{2}{*}{ Family Planning Method } & \multicolumn{2}{|c|}{$\begin{array}{l}\text { Unintended Pregnancies } \\
\text { Rates per } 100 \text { Women }\end{array}$} & \multirow{2}{*}{$\begin{array}{c}\text { Ever Used } \\
\text { Percentage } \\
2010 \text { DHS } \\
\text { Data }\end{array}$} & \multirow{2}{*}{$\begin{array}{c}\text { Ever Used } \\
\text { Percentage } \\
\text { Analysis } \\
\text { Sample }\end{array}$} \\
\hline & $\begin{array}{l}\text { Perfect } \\
\text { Use }\end{array}$ & $\begin{array}{l}\text { Typical } \\
\text { Use }\end{array}$ & & \\
\hline Total Abstinence & 0 & 0 & 0.0 & 0.0 \\
\hline Implants & 0.05 & 0.05 & 1.9 & 1.7 \\
\hline Male Sterilization & 0.10 & 0.15 & 0.1 & 0.1 \\
\hline Female Sterilization & 0.50 & 0.50 & 8.7 & 13.9 \\
\hline IUD & 0.60 & 0.80 & 0.3 & 0.3 \\
\hline Lactational Amenorrhoea & 0.90 & 2 & 0.0 & 0.0 \\
\hline Injections & 0.05 & 6 & 42.9 & 40.9 \\
\hline Pill & 0.30 & 9 & 6.4 & 4.6 \\
\hline Diaphragm & 6 & 12 & 0.0 & 0.0 \\
\hline Male Condom & 2 & 18 & 9.4 & 4.7 \\
\hline Female Condom & 5 & 21 & 0.3 & 0.1 \\
\hline Withdrawal & 4 & 22 & 5.6 & 4.7 \\
\hline Periodic Abstinence/Rhythm & 5 & 24 & 0.0 & 0.0 \\
\hline Foam and Jelly & 18 & 28 & 0.0 & 0.0 \\
\hline Other Traditional & 85 & 85 & 0.0 & 0.0 \\
\hline No Contraception ${ }^{a}$ & 85 & 85 & 37.1 & 32.3 \\
\hline
\end{tabular}

Values in first two columns adapted from Trussell (2011). Values in the last two columns represent the percentage of women in the 2010 Malawi DHS who have ever used that method during the 80 months preceding the survey and the same percentage for women included in the analysis (currently married and fecund, with at least one child, and who was married at age 12 or later), respectively. ${ }^{a}$ Proportion of women who have never used any contraception in the 80 months preceding the survey.

progressed to $34.24 \%$ in 2008 , before jumping up to $37.64 \%$ and $41.64 \%$ in 2009 and 2010 , respectively.

Not all methods reported in Table 1 were used by survey respondents, although a number of them were. Table 2 provides a more detailed breakdown of the most common methods used across a variety of categories including the urban/rural divide, largest ethnic groups, knowledge about HIV/AIDS, the woman's education, various age groups, and household wealth. However, we limited the contraceptive calendar to the previous two years, rather than the previous 80 months to limit recall concerns; our analysis is based on this calendar window. There are not too many obvious usage patterns; however, we do see that non-use falls with wealth and education, while most other methods become more common as wealth and education increases. Similarly, we see greater use of most methods (lower non-use) in 


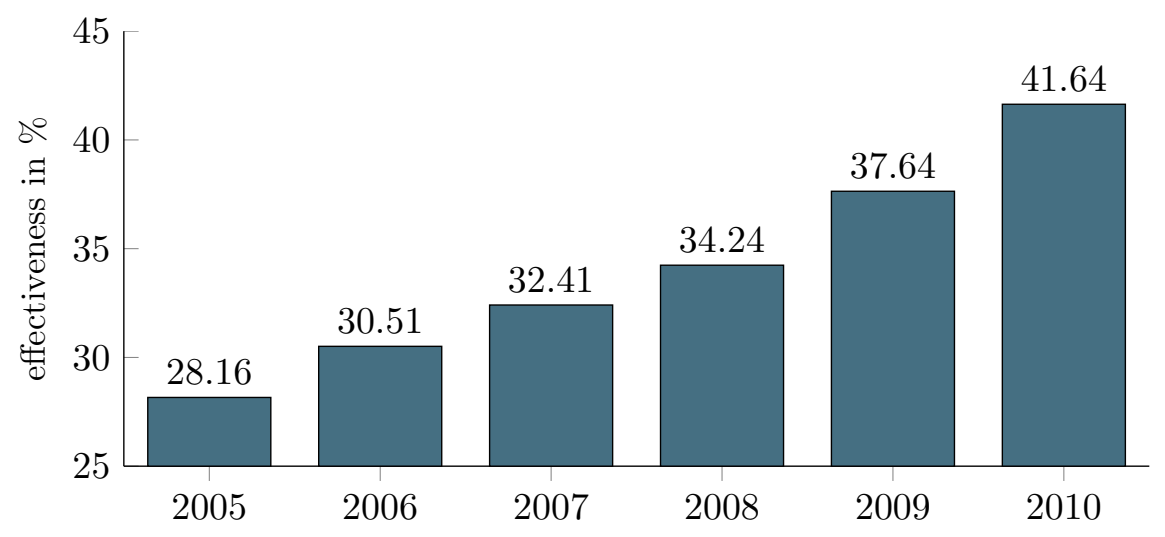

Figure 1: Average Contraceptive effectiveness in Malawi 2005-2010

urban areas, relative to rural areas. Furthermore, although the proportions of male condom users are small, the usage patterns suggest that the more a women knows about HIV/AIDS, the less likely it is that a male condom was the form of contraception used at the time of her last intercourse.

\subsection{Additional Controls}

Our theoretical model suggests that the contraception effectiveness dynamics observed in Figure 1 are driven by individual behaviours determined by factors, such as fecundity, frequency of intercourse, the cost of contraception and risk preferences. We approximate a woman's natural fecundity by the time-to-first-pregnancy (TTFP), which is defined as the length of time from starting unprotected intercourse till first conception, where larger TTFPs imply less fecund women; for the analysis we use the log of the number of months. The TTFP is mainly determined by biological fecundity, which makes it one of the most common methods for measuring human fecundity (Basso et al., 2000; Keiding et al., 2012). However, in order to control for the fact that the duration time to first pregnancy might also be influenced by the woman's contraceptive behaviour, we restrict our sample to sexually active married women, whose age at first intercourse coincides with or is higher than the age at marriage. In other words, we assume that the primary objective of marriage is to start a family, and, therefore, contraceptive use among young married women is likely to be very low before their first pregnancy. For that reason, along with the need to capture TTFP, we also limit our analysis to women who have had at least one child, and were married at ages that could lead 
Table 2: Contraceptive Usage and Non-usage in the Sample: Percentages within Groups

\begin{tabular}{|c|c|c|c|c|c|c|}
\hline & Non-Use & Injection & $\begin{array}{r}\text { Female } \\
\text { Sterilization }\end{array}$ & $\begin{array}{r}\text { Male } \\
\text { Condom }\end{array}$ & Withdrawal & Pill \\
\hline Urban & 33.1 & $\overline{440.5}$ & 13.7 & 4.9 & 4.7 & $\overline{4.5}$ \\
\hline Rural & 25.7 & 43.8 & 16.3 & 3.4 & 4.3 & 5.4 \\
\hline Christian & 30.7 & 41.2 & 14.5 & 4.9 & 5.0 & 4.8 \\
\hline Muslim & 48.3 & 37.1 & 8.4 & 2.5 & 1.7 & 2.5 \\
\hline Chewa & 33.7 & 45.1 & 14.1 & 1.7 & 2.3 & 3.3 \\
\hline Lomwe & 34.8 & 45.5 & 12.0 & 3.6 & 0.5 & 3.9 \\
\hline Tumbuka & 23.6 & 30.0 & 17.2 & 12.5 & 14.3 & 6.6 \\
\hline Zero/One Correct ${ }^{a}$ & 33.5 & 52.7 & 0.8 & 6.7 & 4.6 & 4.3 \\
\hline Two Correct ${ }^{a}$ & 31.7 & 44.4 & 10.1 & 4.2 & 4.9 & 5.1 \\
\hline Three Correct ${ }^{a}$ & 31.8 & 18.1 & 39.0 & 2.9 & 4.4 & 3.9 \\
\hline Four Correct ${ }^{a}$ & 34.0 & 41.4 & 12.2 & 3.8 & 5.3 & 2.6 \\
\hline Age $\leq 25$ & 30.3 & 41.1 & 13.9 & 3.6 & 5.6 & 5.6 \\
\hline $25<$ Age $\leq 36$ & 32.1 & 40.9 & 14.3 & 5.7 & 4.0 & 4.9 \\
\hline Age $>36$ & 32.7 & 40.9 & 14.1 & 4.8 & 5.5 & 3.4 \\
\hline No Schooling & 38.7 & 34.0 & 19.9 & 1.8 & 2.0 & 4.4 \\
\hline Primary & 32.3 & 41.3 & 13.5 & 5.1 & 5.0 & 4.2 \\
\hline Secondary & 24.0 & 47.0 & 8.9 & 6.3 & 6.1 & 7.0 \\
\hline Wealth Q1 & 37.1 & 41.9 & 10.4 & 3.8 & 3.5 & 4.7 \\
\hline Wealth Q2 & 36.1 & 42.4 & 10.1 & 3.8 & 4.9 & 3.7 \\
\hline Wealth Q3 & 33.0 & 42.8 & 11.4 & 4.8 & 5.7 & 4.1 \\
\hline Wealth Q4 & 29.4 & 39.9 & 17.8 & 6.1 & 3.8 & 4.4 \\
\hline Wealth Q5 & 25.9 & 36.8 & 20.1 & 4.8 & 5.5 & 6.4 \\
\hline
\end{tabular}

Percentages never users (column 1) of any contraception and ever users (columns 2-6) of any particular type of contraceptive method. Figures based on analysis sample, and percentages are calculated across particular subgroups of the data. ${ }^{a}$ Refers to number of HIV/AIDS transmission questions the respondent answered correctly (there were five questions in total.

to pregnancy. ${ }^{7}$

Another variable of interest in our analysis is the frequency of intercourse, which captures a woman's sexual behaviour. As a measure of a woman's exposure to sexual activity, the DHS used only records the answer to a question probing coital recency. Thus, we use intercourse recency (days since last intercourse) as a proxy for an individual's frequency of intercourse. Furthermore, in our triangular simultaneous equations set-up, coital frequency is an endogenous variable, which, in turn, is expected to be determined by the menstrual cycle, income, the latent taste for sexual intercourse and a number of other factors. We use the education of the woman and her partner to approximate the couple's income, along with household

\footnotetext{
${ }^{7}$ For example, there are reported marriages and first sexual encounters at the age of 8 , so we required women to at least be 11, although most of these observations would have been dropped for previous reasons.
} 
wealth, even though the latter may not necessarily describe current income flows, while the former also accounts for knowledge related to pregnancy and contraception. Presumably, a women's knowledge about the relationship between the menstrual cycle and the probability of pregnancy is an important determinant of her sexual activities. Thus, we incorporate that knowledge in the model, as well.

Furthermore, the model suggests that risk preferences are also likely to matter to the woman's decisions. Although the DHS does not explicitly capture risk preferences, we are able to uncover information about ethnicity and religion, which, through tradition and other teachings, are likely to influence risk preferences; therefore, we include religion and ethnicity. Since there are a series of HIV/AIDS transmission questions, we use them to partially control for risk, assuming that the more knowledgeable are more concerned about HIV/AIDS risks, and, therefore are more risk averse. We also incorporate the woman's age in the analysis, which should also capture additional aspects of preferences.

Finally, although the DHS does not collect information on the cost of family planning services, it is an important determinant of demand. Even though McKelvey et al. (2012) find negligible price effects, they do find evidence that availability has an important effect on contraception use. Fortunately, one can infer an index for the combined economic and non-economic costs of contraception in a given geographical area by using the percentage of women with unmet need for contraception (Casterline and Sinding, 2000; Bongaarts, 2010). The demand for contraception in the DHS is measured by the level of contraceptive use that would prevail if every fecund woman, who wants to avoid pregnancy, were currently using contraception. Couples whose demand for contraception is not satisfied have an 'unmet need' for contraception, and the cost of contraception to individuals is the proximate determinant of the unmet need (Bongaarts, 2010). Thus, we assume that geographical variations in the percentage of women with unmet need for contraception reveals information about spatial contraceptive (opportunity) cost differentials. In the index, we combine both unmet need for spacing and limiting births. All the covariates used for estimation are summarized in Table 3 and are separated according to whether or not the women has or has not ever used contraception (as determined by the information reported in the contraceptive calendar), while correlation coefficients are presented in Appendix Tables D.1 - D.5. 
Table 3: Descriptive Statistics of Analysis Sample: Never-users Compared to Ever-Users

\begin{tabular}{|c|c|c|c|c|}
\hline & \multicolumn{2}{|c|}{ Never-users } & \multicolumn{2}{|c|}{ Ever-users } \\
\hline & Mean & S.D. & Mean & S.D. \\
\hline Contraceptive Effectiveness & 0.168 & $(0.10)$ & 0.802 & $(0.22)$ \\
\hline Percent Unmet Need & 10.892 & $(7.32)$ & 9.061 & $(6.49)$ \\
\hline Days Since Last Sex & 5.027 & $(4.53)$ & 4.997 & $(4.51)$ \\
\hline Time to First Birth (Days) & 81.286 & $(119.60)$ & 91.463 & $(260.53)$ \\
\hline Days Since Last Cycle & 21.205 & $(15.78)$ & 19.259 & $(13.84)$ \\
\hline Ideal Number of Kids & 4.317 & $(1.16)$ & 4.234 & $(1.21)$ \\
\hline Want More Kids & 0.720 & $(0.45)$ & 0.616 & $(0.49)$ \\
\hline Urban Resident & 0.084 & $(0.28)$ & 0.115 & $(0.32)$ \\
\hline Own Age (years) & 30.312 & $(7.96)$ & 30.546 & $(7.86)$ \\
\hline Partner Age (years) & 36.177 & $(9.73)$ & 36.313 & $(9.29)$ \\
\hline Age Difference $^{a}$ & 5.864 & $(5.22)$ & 5.767 & $(4.51)$ \\
\hline Own Ed: No Schooling & 0.193 & $(0.40)$ & 0.146 & $(0.35)$ \\
\hline Own Ed: Primary & 0.711 & $(0.45)$ & 0.710 & $(0.45)$ \\
\hline Own Ed: Secondary & 0.095 & $(0.29)$ & 0.144 & $(0.35)$ \\
\hline Partner Ed: None & 0.126 & $(0.33)$ & 0.099 & $(0.30)$ \\
\hline Partner Ed: Primary & 0.642 & $(0.48)$ & 0.622 & $(0.48)$ \\
\hline Partner Ed: Secondary & 0.218 & $(0.41)$ & 0.252 & $(0.43)$ \\
\hline Partner Ed: Tertiary & 0.014 & $(0.12)$ & 0.027 & $(0.16)$ \\
\hline Wealth Quantile 1 & 0.196 & $(0.40)$ & 0.158 & $(0.37)$ \\
\hline Wealth Quantile 2 & 0.235 & $(0.42)$ & 0.199 & $(0.40)$ \\
\hline Wealth Quantile 3 & 0.226 & $(0.42)$ & 0.219 & $(0.41)$ \\
\hline Wealth Quantile 4 & 0.200 & $(0.40)$ & 0.230 & $(0.42)$ \\
\hline Wealth Quantile 5 & 0.143 & $(0.35)$ & 0.195 & $(0.40)$ \\
\hline Catholic & 0.199 & $(0.40)$ & 0.200 & $(0.40)$ \\
\hline CCA Presbyterian & 0.138 & $(0.35)$ & 0.166 & $(0.37)$ \\
\hline Anglican Church & 0.034 & $(0.18)$ & 0.028 & $(0.17)$ \\
\hline Seventh Day/Baptist & 0.058 & $(0.23)$ & 0.078 & $(0.27)$ \\
\hline Muslim & 0.126 & $(0.33)$ & 0.064 & $(0.25)$ \\
\hline Ethnicity: Chewa & 0.373 & $(0.48)$ & 0.349 & $(0.48)$ \\
\hline Ethnicity: Tumbuka & 0.092 & $(0.29)$ & 0.142 & $(0.35)$ \\
\hline Ethnicity: Lomwe & 0.142 & $(0.35)$ & 0.127 & $(0.33)$ \\
\hline Ethnicity: Tonga & 0.024 & $(0.15)$ & 0.020 & $(0.14)$ \\
\hline Ethnicity: Yao & 0.105 & $(0.31)$ & 0.068 & $(0.25)$ \\
\hline Ethnicity: Nkhonde & 0.053 & $(0.22)$ & 0.049 & $(0.22)$ \\
\hline Ethnicity: Ngoni & 0.012 & $(0.11)$ & 0.025 & $(0.16)$ \\
\hline Zero/One Correct ${ }^{b}$ & 0.056 & $(0.23)$ & 0.039 & $(0.19)$ \\
\hline Two Correct ${ }^{b}$ & 0.104 & $(0.31)$ & 0.096 & $(0.30)$ \\
\hline Three Correct ${ }^{b}$ & 0.227 & $(0.42)$ & 0.249 & $(0.43)$ \\
\hline Four Correct ${ }^{b}$ & 0.488 & $(0.50)$ & 0.492 & $(0.50)$ \\
\hline Five Correct $^{b}$ & 0.125 & $(0.30)$ & 0.123 & $(0.29)$ \\
\hline Don't Know ${ }^{c}$ & 0.103 & $(0.17)$ & 0.090 & $(0.17)$ \\
\hline During Period $^{c}$ & 0.031 & $(0.49)$ & 0.030 & $(0.50)$ \\
\hline After Period $^{c}$ & 0.404 & $(0.35)$ & 0.436 & $(0.35)$ \\
\hline Middle Cycle ${ }^{c}$ & 0.147 & $(0.37)$ & 0.147 & $(0.37)$ \\
\hline Before Period $^{c}$ & 0.166 & $(0.36)$ & 0.168 & $(0.33)$ \\
\hline Any Time ${ }^{c}$ & 0.000 & $(0.00)$ & 1.000 & $(0.00)$ \\
\hline
\end{tabular}

The first two columns contain means and standard deviations for women who did not use any contraception in the months prior to the survey, as recorded in the contraceptive calendar, while the last two columns contain the same information for women who at least used some form of contraception during that period. ${ }^{a}$ To determine the age difference, we subtract the woman's age from her partner's age. ${ }^{b}$ Refers to the number of HIJ AIDS transmission questions the respondent answered correctly (there were five questions in total). ${ }^{c}$ Refers to survey question about the best time during the menstrual cycle to become pregnant. 


\section{Empirical Results}

Although the table does not provide causal evidence, the differences across user types provides initial support for the theoretical model, while pointing to reasonability in the measure of contraceptive effectiveness. The latter is far lower amongst the never users than the ever users, for example. The percent of unmet need is lower for ever-users, while ever-users are younger. The descriptive statistics also suggest that ever-users are more educated (as are their partners) and wealthier. There are some differences across ethnicity and religion, and we also see that knowledge about AIDS is higher amongst ever-users.

\subsection{First Stage Conditional CDF}

The small correlation coefficients in Appendix Tables D.1 - D.5 suggest that the relationship among the variables could very well be nonlinear, which is also suggested by the nonseparable expressions in equation (3), although endogeneity could also explain the small coefficients. To address these different possibilities, we undertake nonparametric estimation of our triangular simultaneous equation model of the demand for contraceptive effectiveness. In the first step, we use the kernel estimator proposed by Li and Racine (2008) to nonparametrically estimate the conditional cumulative distribution function (CDF) of the logarithm of recency, given a range of variables capturing the women's preferences, the costs of contraception, socioeconomic status, and natural fecundity. Furthermore, we include the log of the number of days since the end of the last menstrual cycle to account for the plausibility that sexual activity is tied to child rearing. The highest likelihood of pregnancy occurs around 14 days later, which is approximately 2.6 log days. As seen in Figure 2, the conditional cumulative distribution of log recency stabilizes just below 3 log days, and, in fact, reduces farther on. These results have implications for interpretation related to our choice of instrument. We discuss this further, below.

As noted before, optimal bandwidths were calculated using leave-one-out least-squares cross-validation, which has the benefit of smoothing out irrelevant predictors. The calculated bandwidths, following Li et al. (2013), are presented in Table 4, along with the minimum 
and maximum values of that variable; in the case of categorical variables, the min and max provide information on the number of categories. Roughly speaking, the larger the bandwidth relative to the range of the data (possibly even exceeding the range of the data), the more the variable is smoothed.

Table 4: First Stage Conditional Distribution Function Bandwidths

\begin{tabular}{lrrr}
\hline Variables $-(Z)$ & Bandwidths & $\min (Z)$ & $\max (Z)$ \\
\hline $\log ($ Days Last Sex) & 0.351 & 0.00 & 3.09 \\
$\log$ (Days Since Last Cycle) & 0.591 & 0.00 & 5.60 \\
Percent Unmet Need & 17.303 & 0.00 & 42.86 \\
$\log$ (Time to First Pregnancy) & 0.866 & 2.20 & 5.25 \\
Want More Children & 0.688 & 0 & 1 \\
Own Age $^{a}$ & 0.908 & -26 & 45 \\
Own Education $^{b}$ & 1.000 & 0 & 2 \\
Partner Education $^{b}$ & 0.368 & 0 & 3 \\
Urban Resident $^{b}$ & 0.209 & 0 & 1 \\
Wealth Quantile $^{a}$ & 1.000 & 0 & 4 \\
Religion $^{b}$ & 0.514 & 0 & 5 \\
Ethnicity $^{b}$ & 0.084 & 0 & 7 \\
AIDS Knowledge $^{a}$ & 1.000 & 0 & 4 \\
Cycle Knowledge $^{b}$ & 0.408 & 0 & 5 \\
\hline Optin $^{b}$ & & 0
\end{tabular}

Optimal bandwidths from the nonparametric estimation of the conditional cumulative distribution function of the recency of sexual activity (the log of the number of days since most recent intercourse). Bandwidths calculated following Li et al. (2013). ${ }^{a}$ denotes an ordered categorical variable (meaning the values are obviously rankable), while ${ }^{b}$ represents an unordered categorical variable (meaning the values are not rankable.

The bandwidths, on their own, do not provide much evidence of the appropriateness of the first stage. Therefore, we provide a series of two-dimensional illustrations of the conditional cumulative distribution function. Because there are a number of covariates in the model, each two-dimensional illustration requires an assumption over the other variables. For these illustrations, all presented in Appendix Figures A.1 - A.3, we assume that each of the other variables in the model is held at its median value. ${ }^{8}$ Although the primary reason for estimating a conditional cumulative distribution function was to capture the distribution of the residual, which is used as the control function in the second-stage, interpreting the estimates, even when illustrated, may not be entirely obvious.

Recall the definition of a conditional cumulative distribution function $F(y \mid w)=\operatorname{prob}[Y \leq$

\footnotetext{
${ }^{8}$ In the case of a multi-valued categorical value such as ethnicity or religion, the mode (most common category) is used, instead.
} 


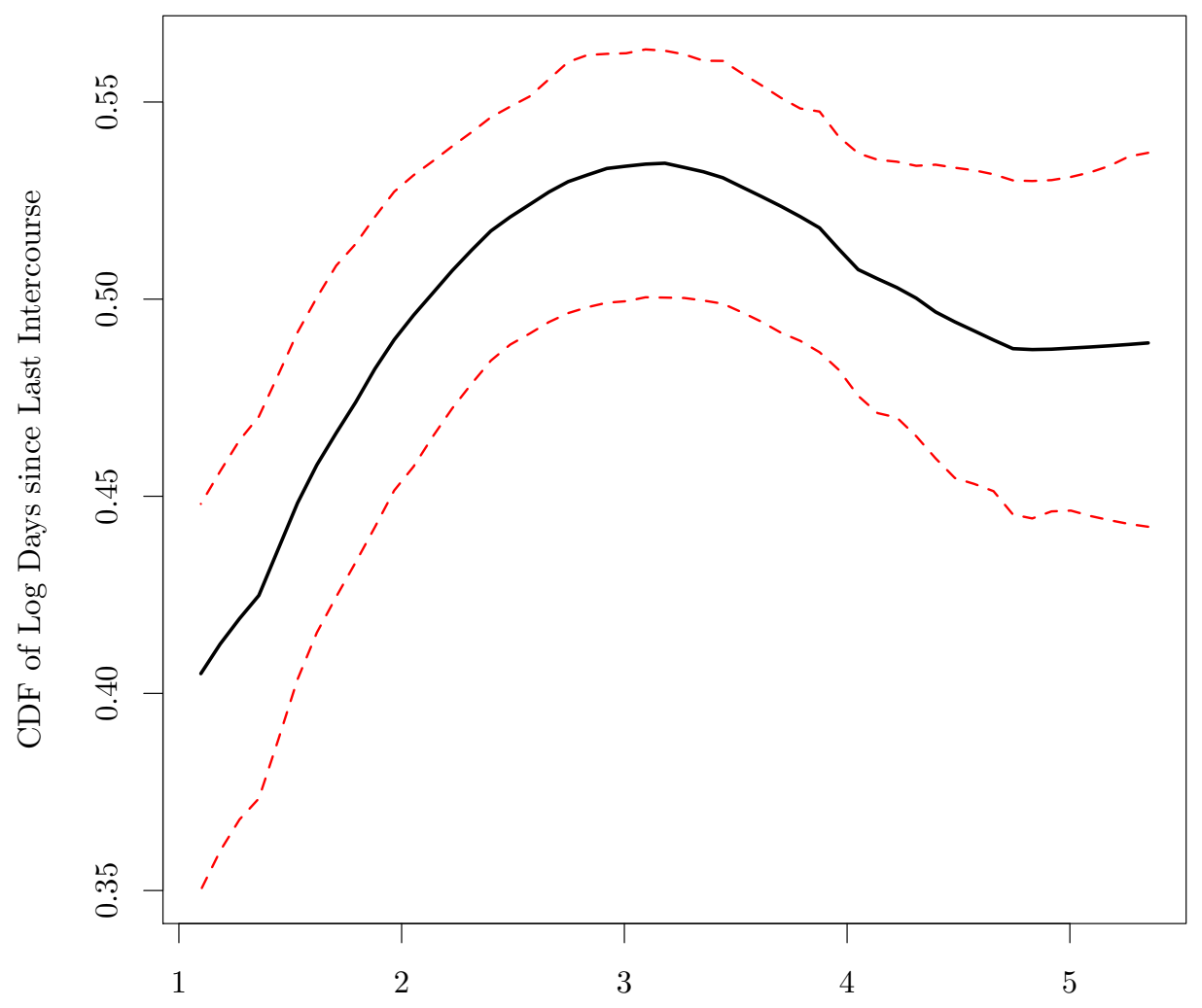

(Log) Days Since Last Menstrual Cycle

Figure 2: First-Stage Conditional Cumulative Distribution Function. Illustration of conditional cumulative distribution function of sexual intercourse recency (log days since most recent sex). Illustrations contain 95\% confidence intervals around estimated conditional CDF values; the confidence intervals are bootstrapped with 399 replications. For each of the distributions, the remaining variables in the model are held at their median values. For the estimated bandwidths, see Table 4 .

$y \mid W \leq w]$ and note that all of the variables (other than the illustrated conditioning variable), including $y$, are held at their median in the illustrations; therefore, the conditional cumulative distribution plots illustrate $F(y \mid w)=\operatorname{prob}\left[Y \leq y_{\text {med }} \mid W \leq w\right]$. Returning to the illustrations, in our case, with the exception of religion, ethnicity and the end of the previous menstrual cycle, few other covariates are associated with the recency (or lack thereof) of sexual activity. In other words, the illustrated conditional cumulative distributions are largely unaffected by these additional variables. ${ }^{9}$ We find the results appealing, since they suggest that sexual

\footnotetext{
${ }^{9}$ Estimating the first stage of a two-stage least squares model, see Appendix Table C.1, suggests very similar features.
} 
activity is driven primarily by preferences, rather than economic circumstances. Of most interest in the first stage of the analysis is the number of days since the end of the preceding menstrual cycle (in log days), our instrument. Our illustration shows that the probability a women's most recently reported sexual encounter occurred earlier than the median value (which is three days), is increasing for women at the earliest stages of their menstrual cycle, up to about $3 \log$ days (or 20 days). In other words, sexual activity is reported to be more recent for women, whose period recently ended. We also see the opposite beyond 3 log days: sexual activity is reported to be more recent for women whose most recent menstrual cycle ended at least three weeks earlier. If sexual activity was primarily for the purposes of childbearing and pregnancy, rather than the $U$-shape, we would expect to see an inverted $U$-shape.

\subsection{Second Stage Local Linear Regression}

For the estimation of the outcome equation, we use local linear estimators as described in Li and Racine (2004) with fixed bandwidths automatically selected through leave-oneout least-squares cross-validation. The estimation results are summarized in Table 5, as well as Figure 3. The table includes calculated bandwidths for each of the variables in the model, their ranges (i.e., the minimum and maximum values) and the result of nonparametric significance tests of the variables in the model (Racine, 1997; Racine et al., 2006), while the figure contains partial regression plots explained further, below. As can be seen from the results, all of the variables are statistically significant at conventional levels.

Under the assumption that our control variable properly accounts for the endogeneity between sexual activity and the choice of contraceptive method, the second-stage results can be interpreted causally. However, the direction of that effect cannot be determined directly from either the bandwidths or the tests of statistical significance. Therefore, as with the conditional cumulative distribution function, the results are presented across a series of twodimensional partial regression illustrations, holding the remaining dependent variables at their median (or mode, in the case of categorical variables). We describe the most relevant to our model here - see Figure 3 - and point the reader to the appendix to view the others; those plots are available in Figures B.1 - B.3.

The partial regression plots are illustrated together with bootstrapped variability bounds, where 399 bootstrap replications were used. Firstly, we expected effectiveness to relate to both 
Table 5: Second Stage Significance Test and Cross-Validated Bandwidths

\begin{tabular}{lrrrr}
\hline Variables $-(X)$ & Bandwidths & $\max (X)$ & $\min (X)$ & P-Value \\
\hline $\log ($ Days Since Last Intercourse) & 22251 & 3.09 & 0.00 & 0.025 \\
Percent Unmet Need & 16.770 & 42.86 & 0.00 & $<0.001$ \\
$\log$ (Time to First Pregnancy) & 182597 & 5.25 & 2.20 & $<0.001$ \\
Want More Children & 0.071 & 1.00 & 0.00 & $<0.001$ \\
Partner Age Difference & 0.964 & 45 & -26 & $<0.001$ \\
Own Education & 0.876 & 2.00 & 0.00 & 0.090 \\
Partner Education & 0.283 & 3.00 & 0.00 & $<0.001$ \\
Urban Resident & 0.126 & 1.00 & 0.00 & $<0.001$ \\
Wealth Quantile & 0.674 & 4.00 & 0.00 & $<0.001$ \\
Religion & 0.335 & 5.00 & 0.00 & $<0.001$ \\
Ethnicity & 0.136 & 7.00 & 0.00 & $<0.001$ \\
AIDS Knowledge & 1.000 & 4.00 & 0.00 & 0.008 \\
Cycle Knowledge & 0.419 & 5.00 & 0.00 & $<0.001$ \\
Control Function & 0.906 & 0.98 & 0.06 & 0.010 \\
\hline
\end{tabular}

Optimal bandwidths from the nonparametric estimation of the conditional cumulative distribution function of the recency of sexual activity (the log of the number of days since most recent intercourse). Bandwidths calculated following Li et al. (2013).

opportunity costs and infecundity (holding child desires constant and assuming women are not completely opposed to additional children), and these expectations are borne-out empirically. Specifically, women facing higher opportunity costs (proxied by greater unmet need) are using less effective contraceptive methods (Figure 3b). Additionally, less fecund women, who are proxied by having relatively longer times to reach their first pregnancy, are using contraceptive methods with lower expected effectiveness (Figure 3c). Furthermore, the control function is negatively related to effectiveness. It accounts for the simultaneity expected between the choice of contraceptive effectiveness and the recency of sexual intercourse. Its statistical significance - see Table 5 - suggests that sexual activity is endogenous in the determination of the effectiveness of contraception, as expected, while the direction implies that ignoring this endogeneity would result in downward bias, when estimating the effect of sexual activity on contraceptive effectiveness.

Finally, the causal effect of sexual activity (measured in log days since most recent intercourse) on contraceptive effectiveness is positive. Although the theoretical model implied that the frequency of sexual activity would increase contraceptive effectiveness, we estimate a negative effect of our proxy for frequency (recency of activity) on effectiveness. However, interpreting this result in the presence of our instrument makes sense of this seeming con- 


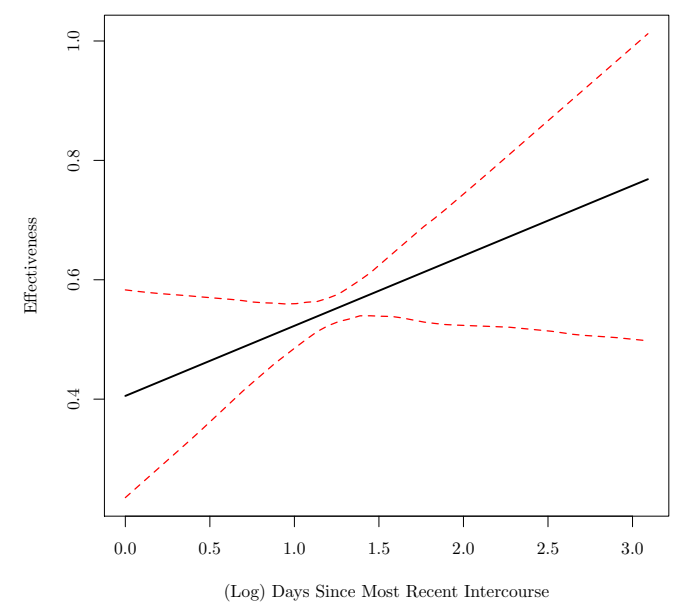

(a)

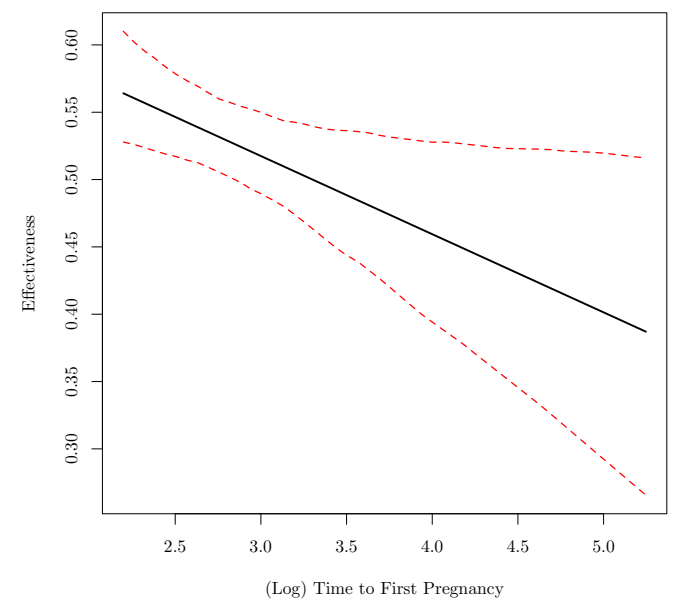

(c)

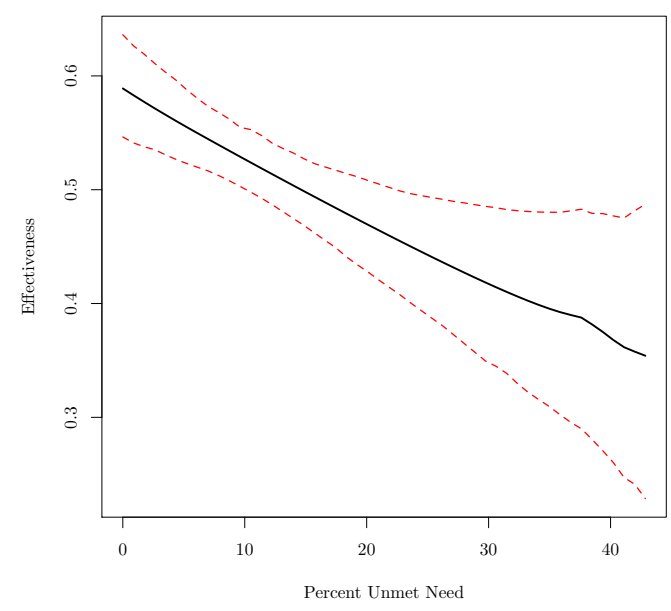

(b)

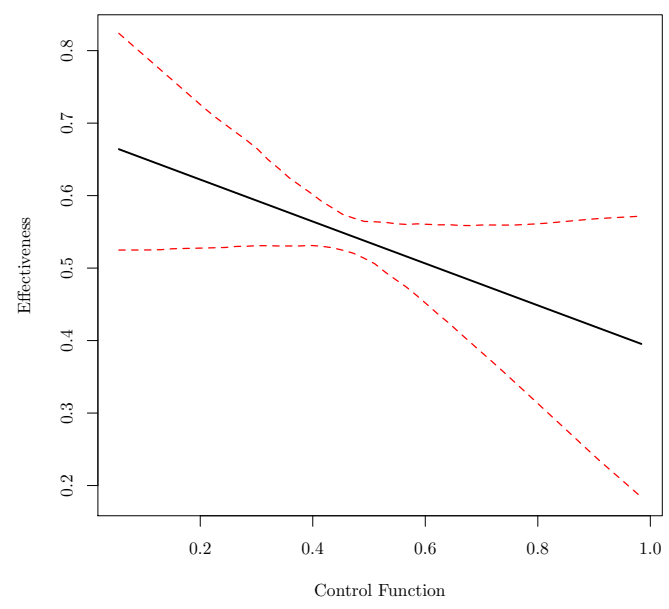

(d)

Figure 3: Partial local linear nonparametric regression plots of contraceptive effectiveness with bootstrapped 95\% error bounds. Error bounds are based on 399 bootstrap replications, while other variables in the model are held at their median values.

tradiction between the theoretical and the empirical. Firstly, our instrument suggests that sexual activity amongst the women in the Malawian Demographic and Health Surveys is not entirely for purposes of procreation. Since the instrument captures sexual activity that is not meant to lead to birth, we can surmise the effect that remains is the effect related to childbearing. In other words, we would expect couples more interested in having another child to be more engaged in sexual activity (and, thus, have reported intercourse to have occurred more recently). In that case, we would expect to see a positive causal effect: less effective 
contraceptive methods being used by couples engaging in more frequent sexual activity.

Secondly, our theoretical model also suggested that risk preferences are an important contributor to both sexual activity and contraceptive effectiveness. Although religion and ethnicity were included in the empirical analysis in an attempt to account for background that might influence risk, we were not able to account for risk directly. Therefore, our empirical analysis could be missing an important variable. Risk preferences are expected, ceteris paribus, to increase the level of contraceptive effectiveness. Thus, more effective contraception methods being used by women who are also not as sexually active supports the notion that women who want to limit their childbearing undertake both self-insurance (engage in less sexual activity) and use more effective contraception.

As noted during the discussion, we had expected nonlinearities in the estimates; however, our results suggest that non-linearities were not uncovered, at least in the second stage, although they were in the reduced form model. For that reason, we also undertook two-stage least squares regression; see Table C.2; Table C.1 contains the reduced form estimates. In agreement with the nonparametric analysis, effectiveness falls with infecundity, as measured by (log) days to first pregnancy, and with the opportunity cost of accessing contraception. On the other hand, effectiveness rises with instrumented log days since most recent intercourse: once the endogeneity of sexual activity is addressed, women use more effective contraception and engage in intercourse less frequently, or vice versa.

\section{Conclusion}

As noted at the outset, speeding up the demographic transition offers opportunities for improved economic growth, gender equality and health in Africa (Bloom et al., 2009; Ashraf et al., 2013; Karra et al., 2017; Canning and Schultz, 2012; Cleland et al., 2012; Chersich et al., 2017), and that transition is likely to depend on contraception adoption (Moultrie et al., 2012). Although adoption is increasing on the continent (Tsui et al., 2017), as has knowledge about contraception (Blackstone et al., 2017), there remains ineffective adoption of fertility limiting preferences (Casterline and Agyei-Mensah, 2017). The focus of this research was on understanding the adoption of effective fertility limiting contraceptives. We have developed a theoretical model to explain the effective adoption decision, which was shown to 
depend on the usual factors, such as prices and preferences (preferences for additional children and risk preferences, in particular), but also on natural fecundity and sexual activity, the latter of which is also subsumed in the theoretical model, and is, therefore, an endogenous determinant of contraceptive effectiveness. We have also estimated an empirical counterpart to the theoretical model. Specifically, we estimated a nonparametric control function model (see Florens et al., 2008; Imbens and Newey, 2009) allowing for nonlinearities in the adoption decision, nonlinearities that were mostly realized in the empirical model's reduced form.

In the theoretical model, the choice of the optimal level of contraceptive effectiveness is realized, subject to the equation of motion of reproductive health capital. The resulting expressions of the demand for family planning services can be used to reproduce some basic stylized facts about individual contraceptive behaviour, specifically, that better (more effective) contraception is more likely to be used if it is less costly to access and is expected to have greater benefits. For example, greater effectiveness is preferred (ceteris paribus) for women who believe they are naturally more fertile. However, once controlling for the endogeneity of sexual activity, we found that women who were more sexual active were likely to be using less effective methods, presumably because these women are trying to have children. Furthermore, the results suggest that Malawian women are, at least partially, able to implement their fertility preferences, and, therefore, we should expect to see further reductions in fertility in Malawi. Malawi may still be 'exceptional', along with the rest of Africa, but our results suggest it is becoming less so.

Access to reproductive health services affords women the opportunity to optimize their lifetime earning opportunities by lowering the costs of long-term career investments and reducing uncertainties regarding the timing of births (Goldin and Katz, 2002; Canning and Schultz, 2012; Behrman, 2015). Thus, analysing the demand for reproductive health care provides a natural channel through which socio-economic factors can be expected to explain observed fertility outcomes. In future empirical work one may be interested in extending our framework to consider other components of reproductive health, namely maternal health care and child health care. It might also be possible to use our framework to analyse the provision of childcare services, as an input to the production function of active time in the formal labour market for working mothers. Further empirical research would also benefit from the inclusion of better controls for the woman's risk preferences. 


\section{References}

Ali, M. M. and Cleland, J. (2010), 'Oral contraceptive discontinuation and its aftermath in 19 developing countries', Contraception 81, 22-29.

Ali, M. M., Cleland, J. and Shah, I. H. (2012), Cause and Consequences of Contraceptive Discontinuation: Evidence from 60 Demographic and Health Surveys, World Health Organization.

Angeles, G., Guilkey, D. K. and Mroz, T. A. (1998), 'Purposive program placement and the estimation of family planning program effects in Tanzania', Journal of the American Statistical Association 93(443), 884-899.

Arrow, K. J. (2006), Optimal capital policy with irreversible investment, in J. N. Wolfe, ed., 'Value, Capital and Growth', 2 edn, Transaction Publishers, New Brunswick, New Jersey, chapter 1.

Ashraf, N., Buessing, M., Field, E. and Leight, J. (2014), 'The psycho-social benefits of access to contraception: Experimental evidence from Zambia', Unpublished Manuscript, Harvard Business School.

Ashraf, N., Field, E. and Lee, J. (2014), 'Household bargaining and excess fertility: an experimental study in Zambia', American Economic Review 104(7), 2210-2237.

Ashraf, N., Field, E. and Leight, J. (2014), 'Contraceptive access and fertility: The impact of supply-side interventions', Unpublished Manuscript, Harvard Business School.

Ashraf, Q. H., Weil, D. N. and Wilde, J. (2013), 'The effect of fertility reduction on economic growth', Population and Development Review 39(1), 97-130.

Baird, S., McIntosh, C. and Özler, B. (2011), 'Cash or condition? evidence from a cash transfer experiment', Quarterly Journal of Economics 126(4), 1709-1753.

Basso, O., Juul, S. and Olsen, J. (2000), 'Time to pregnancy as a correlate of fecundity: Differential persistence in trying to become pregnant as a source of bias', International Journal of Epidemiology 29, 856-861.

Behrman, J. A. (2015), 'Does schooling affect women's desired fertility? evidence from Malawi, Uganda and Ethiopia', Demography 52(3), 787-809.

Bellows, B., Bulaya, C., Inambwae, S., Lissnre, C. L., Ali, M. and Bajracharya, A. (2016), 'Family planning vouchers in low and middle income countries: A systematic review', Studies in Family Planning 47(4), 357-370.

Ben-Porath, Y. (1967), 'The production of human capital and the life cycle of earnings', Journal of Political Economy 75(4), 352-365.

Berkson, J. (1944), 'Application of the logistic function to bio-assay', Journal of the American Statistical Association 39, 357-365.

Bjork, T. (2009), Arbitrage theory in continuous time, third edn, Oxford University Press.

Blackstone, S. R., Nwaozuru, U. and Iwelunmor, J. (2017), 'Factors influencing contraceptive use in sub-Saharan Africa: A systematic review', International Quarterly of Community Health Education 37(2), 79-91. 
Bloom, D. E., Canning, D., Fink, G. and Finlay, J. E. (2009), 'Fertility, female labor force participation, and the demographic dividend', Journal of Economic Growth 14, 79-101.

Bongaarts, J. (2010), 'The causes of education differences in fertility in Sub-Saharan Africa', Vienna Yearbook of Population Research 8, Education and Demography, 31-50.

Bongaarts, J. (2014), 'The impact of family planning programs on unmet need and demand for contraception', Studies in Family Planning 45(2), 247-262.

Bongaarts, J. (2017), 'Africa's unique fertility transition', Population and Development Review 43(S1), 39-58.

Bongaarts, J. and Casterline, J. B. (2012), 'Fertility transition: Is sub-Saharan Africa different?', Population and Development Review 38(Suppplement), 153-168.

Brown, M. S. (2000), 'Coitus, the approximate determinant of conception: Inter-country variance in Sub-Saharan Africa', Journal of Biosocial Science 32(2), 145-159.

Caldwell, J. C., Orubuloye, I. and Caldwell, P. (1992), 'Fertility decline in Africa: A new type of transition?', Population and Development Review 18(2), 211-242.

Canning, D. and Schultz, T. P. (2012), 'The economic consequences of reproductive health and family planning', The Lancet 380(9837), 165-171.

Casterline, J. B. and Agyei-Mensah, S. (2017), 'Fertility desires and the course of fertility decline in sub-Saharan Africa', Population and Development Review 43(S1), 84-111.

Casterline, J. B. and El-Zeini, L. O. (2014), 'Unmet need and fertility decline: A comparative perspective on prospects in Sub-Saharan Africa', Studies in Family Planning 45(2), 227245.

Casterline, J. B. and Sinding, S. W. (2000), 'Unmet need for family planning in developing countries and implications for population policy', Population and Development Review 26, 691-723.

Chersich, M. F., Wabiri, N., Risher, K., Shisana, O., Celentano, D., Rehle, T., Evans, M. and Rees, H. (2017), 'Contraception coverage and methods used among women in South Africa: A national household survey', South African Medical Journal 107(4), 307-314.

Chesher, A. (2003), 'Identification in nonseparable models', Econometrica 71(5), 1405-1441.

Cleland, J., Conde-Agudelo, A., Peterson, H., Ross, J. and Tsui, A. (2012), 'Contraception and health', The Lancet 380(9837), 149-156.

Cleland, J. and Machiyama, K. (2017), 'The challenges posed by demographic change in subSaharan Africa: A concise overview', Population and Development Review 43(S1), 264-286.

Collier, P. and Dercon, S. (2014), 'African agriculture in 50 years: Smallholders in a rapidly changing world?', World Development 63(1), 92-101.

Darroch, J. E. and Singh, S. (2012), 'Trends in contraceptive need and use in developing countries in 2003, 2008, and 2012: an analysis of national surveys', The Lancet 381(9879), 17561762 .

Desai, J. and Tarozzi, A. (2011), 'Microcredit, family planning programs, and contraceptive behavior: evidence from a field experiment in Ethiopia', Demography 48(2), 749-782. 
Do, M. and Kurimoto, N. (2012), 'Women's empowerment and choice of contraceptive methods in selected African countries', International Perspectives on Sexual and Reproductive Health 38(1), 23-33.

Duflo, E., Dupas, P. and Kremer, M. (2015), 'Education, hiv, and early fertility: Experimental evidence from Kenya', American Economic Review 105(9), 2757-2797.

Easterlin, R. A. (1975), 'An economic framework for fertility analysis', Studies in Family Planning 6, 54-63.

Fathalla, M. F., Sinding, S. W., Rosenfield, A. and Fathalla, M. M. (2006), 'Sexual and reproductive health for all: A call for action', The Lancet 368(9552), 2095-2100.

Florens, J., Heckman, J., Meghir, C. and Vytlacil, E. (2008), 'Identification of treatment effects using control functions in models with continuous, endogenous treatment and heterogeneous effects', Econometrica 76, 1191-1206.

Gertler, P. J. and Molyneaux, J. W. (1994), 'How economic development and family planning programs combined to reduce Indonesian fertility', Demography 31(1), 33-63.

Goldin, C. and Katz, L. F. (2002), 'The power of the pill: Oral contraceptives and women's career and marriage decisions', Journal of Political Economy 110(4), 730-770.

Grossman, M. (1972), 'On the concept of health capital and the demand for health', Journal of Political Economy 80(2), 223-255.

Grossman, M. (2000), The human capital model, in A. Culyer and J. Newhouse, eds, 'Handbook of Health Economics', Vol. 1, Elsevier.

Hakim, C. (2010), 'Erotic capital', European Sociological Review 26, 499-518.

Hall, P., Li, Q. and Racine, J. S. (2007), 'Nonparametric estimation of regression functions in the presence of irrelevant predictors', The Review of Economics and Statistics 89, 784-789.

Hayfield, T. and Racine, J. S. (2008), 'Nonparametric econometrics: The np package', Journal of Statistical Software 27(5), 1-32. R package version 0.60-2.

Heckman, J. J., Urzua, S. and Vytlacil, E. (2006), 'Understanding instrumental variables in models with essential heterogeneity', Review of Economics and Statistics 88(3), 389-432.

Heckman, J. J. and Willis, R. J. (1976), Estimation of a stochastic model of reproduction: An econometric approach, in N. E. Terleckyj, ed., 'Household Production and Consumption', Colummbia University Press (for NBER), pp. 99-146.

Imbens, G. W. and Newey, W. K. (2009), 'Identification and estimation of triangular simultaneous equations models without additivity', Econometrica 77(5), 1481-1512.

Kaestner, R. (2013), 'The Grossman model after 40 years: A reply to Peter Zweifel', European Journal of Health Economics 14, 357-360.

Karra, M., Canning, D. and Wilde, J. (2017), 'The effect of fertility decline on economic growth in africa: A macrosimulation model', Population and Development Review 43(S1), 237-263.

Keiding, N., Hansen, O. K. H. and Sorensen, D. N. (2012), 'The current duration approach to estimating time to pregnancy', Scandinavian Journal of Statistics 39(2), 185-204. 
Laporte, A. and Ferguson, B. S. (2007), 'Investment in health when health is stochastic', Journal of Population Economics 20(2), 423-444.

Li, Q., Lin, J. and Racine, J. S. (2013), 'Optimal bandwidth selection for nonparametric conditional distribution and quantile functions', Journal of Business $\mathcal{E}$ Economic Statistics 31, 57-65.

Li, Q. and Racine, J. (2004), 'Cross-validated local linear nonparametric regression', Statistica Sinica 14, 485-512.

Li, Q. and Racine, J. S. (2007), Nonparametric Econometrics, Princetone University Press, Princeton.

Li, Q. and Racine, J. S. (2008), 'Nonparametric estimation of conditional CDF and quantile functions with mixed categorical and continuous data', Journal of Business 83 Economic Statistics 26(4), 423-434.

Liljas, B. (1998), 'The demand for health with uncertainty and insurance', Journal of Health Economics 17, 153-170.

Marshall, M. G. and Cole, B. R. (2014), Global Report 2014: Con ict, Governance, and State Fragility, Center for Systemic Peace, Vienna, VA.

McKelvey, C., Thomas, D. and Frankenberg, E. (2012), 'Fertility regulation in an economic crisis', Economic Development and Cultural Change 61(1), 7-38.

Miller, G. (2010), 'Contraception as development? new evidence from family planning in Colombia', The Economic Journal 120(545), 709-736.

Moffat, P. G. (2005), Economics of prostitution, in S. W. Bowmaker, ed., 'Economics Uncut: A Complete Guide to Life, Death and Misadvanture', Edward Elgar Publishing.

Moultrie, T. A., Sayi, T. S. and Timaeus, I. M. (2012), 'Birth intervals, postponement, and fertility decline in Africa: A new type of transition?', Population Studies: A Journal of Demography 66(3), 241-258.

National Statistical Office (NSO) and ICF Macro (2011), 'Malawi demographic and health survey 2010', Zomba, Malawi and Calverton, Maryland, USA: NSO and ICF Macro [producer and distributor].

Osili, U. O. and Long, B. T. (2008), 'Does female schooling reduce fertility? evidence from Nigeria', Journal of Development Economics 87(1), 57-75.

Palermo, T., Handa, S., Peterman, A., Prencipe, L. and Seidenfeld, D. (2016), 'Unconditional government social cash transfer in Africa does not increase fertility', Journal of Population Economics 29(4), 1083-1111.

Perrin, E. B. and Sheps, M. C. (1964), 'Human reproduction: A stochastic process', Biometrics 20(1), 28-45.

Phillips, J. F., Stinson, W. S., Bhatia, S., Rahman, M. and Chakraborty, J. (1982), 'The demographic impact of the family planning health services project in Matlab, Bangladesh', Studies in Family Planning 13(5), 131-140.

Picone, G., Uribe, M. and Wilson, R. M. (1998), 'The effect of uncertainty on the demand for medical care, health capital and wealth', Journal of Health Economics 17, 171-185. 
Pitt, M. M., Rosenzweig, M. R. and Gibbons, D. M. (1993), 'The determinants and consequences of the placement of government programs in Indonesia', The World Bank Economic Review 7(3), 319-348.

R Core Team (2015), R: A Language and Environment for Statistical Computing, R Foundation for Statistical Computing, Vienna, Austria. ISBN 3-900051-07-0.

URL: http://www.R-project.org/

Racine, J. S. (1997), 'Consistent significance testing for nonparametric regression', Journal of Business and Economic Statistics 15, 369-379.

Racine, J. S., Hart, J. S. and Li, Q. (2006), 'Testing the significance of categorical predictor variables in nonparametric regression models', Econometric Reviews 25, 523-544.

Rossier, C., Senderowicz, L. and Soura, A. (2014), 'Do natural methods count? underreporting of natural contraception in urban Burkina Faso', Studies in Family Planning 45(2), 171-182.

Say, L. and Chou, D. (2011), Universal access to reproductive health, Technical report, World Health Organisation.

Schultz, T. P. (2008), Population policies, fertility, women's human capital, and child quality, in 'Handbook of Development Economics', Elsevier.

Singh, S., Esdgh, G. and Hussain, R. (2010), 'Unintended pregnancy: Worldwide levels, trends, and outcomes', Studies in Family Planning 41(4), 241-250.

Smith, R. and Christou, M. L. (2009), 'Extracting value from their environment: Some observations on pimping and prostitution as entrepreneurship', Journal of Small Business \& Entrepreneurship 22(1), 69-84.

Stephenson, R., Baschieri, A., Clements, S., Hennink, M. and Madise, N. (2007), 'Contextual influences of modern contraceptive use in sub-Saharan Africa', American Journal of Public Health 97(7), 1233-1240.

Stokey, N. L. (2009), The economics of inaction: Stochastic control models with fixed costs, Princeton University Press.

Thomas, D. and Maluccio, J. (1996), 'Fertility, contraceptive choice and public policy in Zimbabwe', World Bank Economic Observer 10(1), 189-222.

Trussell, J. (2007), Contraceptive efficacy, in R. A. Hatcher, J. Trussell, A. L. Nelson, W. Cates, D. Kowal and M. Policar, eds, 'Contraceptive technology: Nineteenth Revised Edition', Ardent Media, New York.

Trussell, J. (2011), 'Contraceptive failure in the United States', Contraception 83, 397-404.

Tshiswaka-Kashalala, G. and Koch, S. F. (2017), 'Contraceptive use and time to first birth', Journal of Demographic Economics 83(2), 149-175.

Tsui, A. O., Brown, W. and Li, Q. (2017), 'Contraceptive practice in sub-Saharan Africa', Population and Development Review 43(S1), 166-191.

United Nations, Department of Economic and Social Affairs, Population Division (2015), World Population Prospects: The 2015 Revision, United Nations, New York. 
World Bank (2014), Doing Business 2015: Going Beyond Ef ciency, The World Bank, Washington, DC.

World Health Organization, Department of Reproductive Health and Research (WHO/RHR) and John Hopkins Bloomberg School of Public Health/Center for Communication Programs (CCP), Knowledge for Health Project (2011), Family Planning: A Global Handbook for Providers (2011 update), CCP and WHO, Baltimore and Geneva. 